\title{
Near-real-time Arctic sea ice thickness and volume from CryoSat-2
}

\author{
Rachel L. Tilling ${ }^{1}$, Andy Ridout ${ }^{1}$, and Andrew Shepherd ${ }^{2}$ \\ ${ }^{1}$ Centre for Polar Observation and Modelling, Department of Earth Sciences, University College London, London, \\ WC1E6BT, UK \\ ${ }^{2}$ Centre for Polar Observation and Modelling, School of Earth and Environment, University of Leeds, Leeds, LS29JT, UK \\ Correspondence to: Rachel L. Tilling (rachel.tilling.12@ucl.ac.uk)
}

Received: 25 January 2016 - Published in The Cryosphere Discuss.: 2 February 2016

Revised: 25 July 2016 - Accepted: 2 August 2016 - Published: 7 September 2016

\begin{abstract}
Timely observations of sea ice thickness help us to understand the Arctic climate, and have the potential to support seasonal forecasts and operational activities in the polar regions. Although it is possible to calculate Arctic sea ice thickness using measurements acquired by CryoSat-2, the latency of the final release data set is typically 1 month due to the time required to determine precise satellite orbits. We use a new fast-delivery CryoSat-2 data set based on preliminary orbits to compute Arctic sea ice thickness in near real time (NRT), and analyse this data for one sea ice growth season from October 2014 to April 2015. We show that this NRT sea-ice-thickness product is of comparable accuracy to that produced using the final release CryoSat- 2 data, with a mean thickness difference of $0.9 \mathrm{~cm}$, demonstrating that the satellite orbit is not a critical factor in determining sea ice freeboard. In addition, the CryoSat-2 fast-delivery product also provides measurements of Arctic sea ice thickness within 3 days of acquisition by the satellite, and a measurement is delivered, on average, within 14,7 and $6 \mathrm{~km}$ of each location in the Arctic every 2,14 and 28 days respectively. The CryoSat-2 NRT sea-ice-thickness data set provides an additional constraint for short-term and seasonal predictions of changes in the Arctic ice cover and could support industries such as tourism and transport through assimilation in operational models.
\end{abstract}

\section{Introduction}

Near-real-time (NRT) measurements of sea ice thickness allow timely assessments of Arctic environmental change and have the potential to improve the skill of short-term forecasts that are, in turn, a resource for operational activities.
The US Navy's Arctic Cap Nowcast/Forecast System (ACNFS) (Posey et al., 2015; Hebert et al., 2015), for example, provides short-term (1-to-7-day) forecasts of conditions such as the location of the sea ice edge, which can improve the safety and efficiency of their operational missions (Posey et al., 2015; U.S. Navy, 2014). Although the ACNFS currently assimilates NRT sea ice concentration data, it has been suggested that forecast model skill could be further improved by also assimilating NRT measurements of sea ice thickness (Day et al., 2014). On slightly longer (seasonal) timescales, forecast models are currently able to predict the area of September sea ice with good confidence if the distribution of sea ice thickness is known in late spring (Sigmond et al., 2013). To initialize such models with known thickness distributions (Chevallier and Salas-Melia, 2012) and analyse their output, rapid and reliable satellite observations are required. Despite these potential benefits, it is nevertheless recognized that the value of NRT sea-ice-thickness observations derived from repeat satellite altimetry does have limits. For example, some model systems show higher forecast skill when initialized with thickness distribution (and for some months volume anomaly) estimates from early summer (Chevallier and Salas-Melia, 2012). Summer is a period when sea-ice-thickness measurements are traditionally unavailable in the Arctic due to the presence of melt ponds (e.g. Tilling et al., 2015). Similarly, although forecasts could benefit the planning of Arctic operations (Meier et al., 2014; Stewart et al., 2007), day-to-day activities require measurements with far greater spatial and temporal sampling than can be achieved using a single satellite altimeter.

A range of Arctic sea-ice-thickness measurements are currently available, with varying spatial and temporal sampling. The Beaufort Gyre Exploration Project (BGEP) has mea- 
sured year-round sea ice draught using three upward looking sonar buoys moored in the Beaufort Sea since 2003 (http: //www.whoi.edu/beaufortgyre). On a larger scale, NASA's Operation IceBridge utilizes a suite of research aircraft each spring (March and April) to produce tracks of sea-icethickness estimates (Kurtz et al., 2013) concentrated around northern Greenland, the ocean region north of the Canadian Archipelago and the Beaufort Sea. Currently the final and "quick look" IceBridge data are available for spring 2009-2012 and spring 2013-2015 respectively. The quick look product is experimental and is designed only to be applicable for time-sensitive projects such as sea ice forecasting. On a larger spatial scale there are currently three publicly available data sets that provide sea-ice-thickness estimates across the whole Arctic Ocean. These are produced by NASA (Kurtz et al., 2014), Germany's Alfred Wegener Institute (AWI) (Ricker et al., 2014) and the UK's Centre for Polar Observation and Modelling (CPOM) (Tilling et al., 2015) using final release data from the European Space Agency's (ESA) CryoSat-2 satellite (Wingham et al., 2006). NASA provide experimental monthly averaged sea-ice-thickness data for March 2014 and March 2015 within a $7.2 \times 10^{6} \mathrm{~km}^{2}$ area of the central Arctic known as the ICESat domain (Kwok et al., 2009). AWI provide monthly averaged thickness data starting from January 2011 with a current lag of about 6 months, and these data again cover a central area of the Arctic Ocean. CPOM provide sea-icethickness estimates for spring (March/April average) and autumn (October/November average) at all latitudes above and including $40^{\circ} \mathrm{N}$ beginning in autumn 2010 , also with a lag of about 6 months, depending on the availability of sea ice concentration data (Cavalieri et al., 1996). Here we use fastdelivery CryoSat-2 data to produce NRT measurements of Arctic sea ice thickness and volume and evaluate the product.

\section{Data and methods}

We use fast-delivery radar altimeter measurements from the ESA CryoSat-2 satellite synthetic aperture radar (SAR) and SAR interferometric (SARIn) altimeter modes (Wingham et al., 2006) to produce NRT estimates of Northern Hemisphere (latitudes above $40^{\circ} \mathrm{N}$ ) sea ice thickness and volume. The data are Level $1 \mathrm{~b}$ and consist of an echo for each point along the ground track of the satellite. Prior to the release of Level $1 \mathrm{~b}$ data, ESA perform some on-ground processing of the raw satellite data. Before 26 March 2015, ESA applied a processing chain known as "Baseline-B" to the raw fast-delivery data and an updated processor, "BaselineC", has been applied since. The number of range bins for each waveform depends on the satellite operating mode and the baseline of the data - Baseline-B SAR mode has 128 bins, Baseline-C SAR mode has 256 bins, Baseline-B SARIn mode has 512 bins and Baseline-C SARIn mode has
1024 bins. The larger number of bins in SARIn mode is due to an increase in the range window for capturing the slope variation in ice sheet margins. To allow for identical processing of both SAR and SARIn mode data acquired over Arctic sea ice, we crop all waveforms to 128 bins, ensuring that the waveforms are positioned at approximately the same location within the 128 bins.

In the fast-delivery data the wet-tropospheric, drytropospheric and inverse-barometer corrections are missing in $94 \%$ of cases for Baseline-B data, but in less than $1 \%$ of cases for Baseline-C data. In these instances, all three of the corrections are missing. The fast-delivery CryoSat-2 data are available from ESA on average $36 \mathrm{~h}$ after acquisition by the satellite, although we run our sea ice processor with a latency of 3 days to ensure sufficient data are available. The main difference between the fast-delivery and final release CryoSat-2 data is the orbits applied. For both data sets, an accurate determination of the satellite orbit is required to determine surface elevations above a reference ellipsoid. For the final release data product, ESA perform a ground-based precise orbit determination (POD), which requires modelling of the forces acting on the satellite as well as a dense set of measurements regarding its position and velocity (Wingham et al., 2006). The primary means of making these measurements is with the on-board Doppler Orbit and Radio positioning Integration by Satellite (DORIS) receiver, which makes measurements of the relative velocity of the satellite using an extensive network of ground beacons. The messages uplinked from the beacons include time signals that allow the DORIS receiver time to be accurately determined. The DORIS receiver also includes software for the real-time, onboard computation of the orbit, known as the DORIS Navigator orbit. The DORIS Navigator orbit is estimated to be accurate to $30 \mathrm{~cm}$ in the radial direction and is included in the fast-delivery CryoSat-2 data to provide good-quality orbit estimates before the POD can be produced. However, the fastdelivery data are more susceptible to orbit dropout, meaning that certain orbits, for which the orientation of the satellite could not be sufficiently determined, are not included in the data set. There is also a difference in the time frame of on-ground processing of the raw fast-delivery and final release data by ESA. Before 22 February 2015, ESA applied the Baseline-B processing chain to the raw final release data, and an updated processor, Baseline- $\mathrm{C}$, has been applied since 1 April 2015. Between these dates, a hybrid processor known as "Baseline-BC" was applied. On average, it takes us $6 \mathrm{~h}$ to process 1 day of data.

The processing steps for fast-delivery CryoSat-2 data are identical to those used for the final delivery data and are described in Tilling et al. (2015). The first step is the computation of sea ice freeboard, which is the difference in elevation between the snow-ice interface and that of the surrounding ocean. We do this by using the return echo shape to discriminate between measurements of the ocean surface and the ice surface (Peacock and Laxon, 2004). We define sea ice re- 


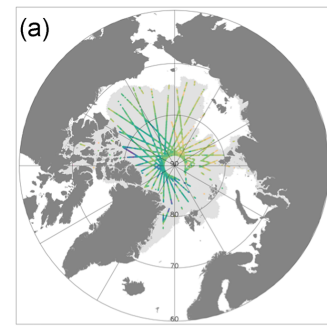

(d)

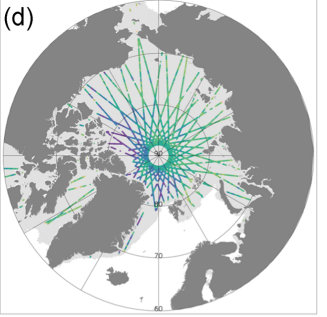

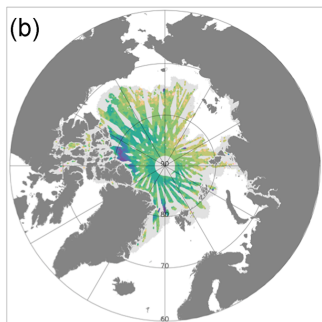

(e)

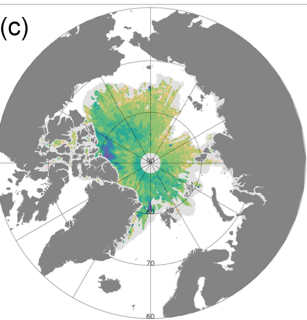

(f)

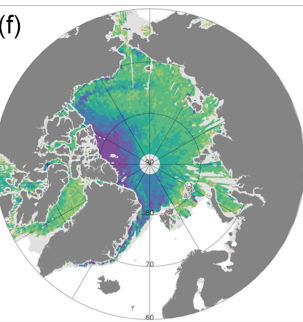

Sea ice thickness $(\mathrm{m})$

$\begin{array}{llllllll}0.00 & 0.50 & 1.00 & 1.50 & 2.00 & 2.50 & 3.00 & 3.50\end{array}$

Figure 1. Near-real-time (NRT) Arctic sea-ice-thickness estimates from CryoSat-2. (a-c) Thickness estimates for the final 2,14 and 28 days of October 2014 respectively. (d-f) Thickness estimates for the final 2, 14 and 28 days of March 2015 respectively. NRT sea-ice-thickness data are output Arctic-wide on a $5 \mathrm{~km}$ square grid. All thickness measurements within a $25 \mathrm{~km}$ radius of the centre of the grid are averaged, with all points receiving equal weight. The sea ice extent mask is shaded in light grey and highlights unmapped areas of the sea ice.

gions as those with a NRT sea ice concentration (Maslanik and Stroeve, 1999) greater than $75 \%$. NRT ice concentration data are taken from the National Snow and Ice Data Center (NSIDC) and are available to us by 01:00 UTC, 2 days after measurement. A correction is applied to each freeboard measurement to account for the reduced speed of the radar pulse as it passes through any snow cover on sea ice. The next step is to convert sea ice freeboard to sea ice thickness. We assume that the ice floes are in hydrostatic equilibrium, under which circumstances sea ice thickness can be calculated using the following:

$T_{\mathrm{i}}=\frac{f_{\mathrm{c}} \rho_{\mathrm{w}}+h_{\mathrm{s}} \rho_{\mathrm{s}}}{\rho_{\mathrm{w}}-\rho_{\mathrm{i}}}$,

where $T_{\mathrm{i}}$ is the sea ice thickness, $f_{\mathrm{c}}$ is the corrected sea ice freeboard, $h_{\mathrm{s}}$ is snow depth, $\rho_{\mathrm{w}}$ is seawater density, $\rho_{\mathrm{s}}$ is snow density and $\rho_{\mathrm{i}}$ is sea ice density. We use a fixed estimate of first-year ice (FYI) density of $916.7 \mathrm{~kg} \mathrm{~m}^{-3}$ (Alexandrov et al., 2010), multi-year ice (MYI) density of $882 \mathrm{~kg} \mathrm{~m}^{-3}$ (Alexandrov et al., 2010) and a fixed seawater density of $1023.9 \mathrm{~kg} \mathrm{~m}^{-3}$ (Wadhams et al., 1992). To obtain snow depth and density we average the values from a climatology (Warren et al., 1999) that fall within the ICESat domain, where the climatology is constrained by in situ measurements. Snow depth is halved over FYI to account for reduced snow accumulation (Kurtz and Farrell, 2011; Webster et al., 2014). NRT ice-type data from the Norwegian Meteorological Service Ocean and Sea Ice Satellite Application Facility (http: //osisaf.met.no/p/ice/\#type) are used to classify FYI and MYI for each individual freeboard measurement, and this data set becomes available to us by 01:00 UTC the day after measurement. During the sea ice melt season it becomes difficult to discriminate between measurements of the ocean and the ice due to melt ponds that form on the sea ice surface, and because of this we do not currently produce measurements of sea ice thickness between May and September. We compute NRT estimates of sea ice on a $5 \mathrm{~km}$ square grid encompassing the entire Arctic region (Fig. 1). To obtain grid values, we average all thickness measurements within a $25 \mathrm{~km}$ radius of the centre of each grid cell, with all points receiving equal weighting. Although this resolution is coarser than the maximum afforded by the CryoSat- 2 altimeter and the satellite orbit (Wingham et al., 2006), it allows the NRT sea-icethickness product to be compared with estimates computed from the entire archive of CryoSat-2 data which, because it extends over a greater time period, has been evaluated with respect to in situ observations (Tilling et al., 2015).

We then compute sea ice volume Arctic-wide and within fixed oceanographic basins (Nurser and Bacon, 2014; Tilling et al., 2015) by averaging individual thickness and concentration values during each calendar month on a $0.1^{\circ} \times 0.5^{\circ}$ grid and defining the sea ice margin by applying a $15 \%$ sea ice concentration mask using data from the 15th day of each month. Empty thickness grid cells within the sea ice extent mask, including those north of $88^{\circ} \mathrm{N}$, are filled by nearestneighbour interpolation with a maximum search radius of $300 \mathrm{~km}$. Monthly estimates of sea ice volume are then cal- 
culated by summing the product of the ice thickness, the ice concentration and the ice area within the sea ice extent mask.

We estimate monthly errors in sea ice volume by considering the contributions due to uncertainties in sea ice freeboard $(\sim 9 \mathrm{~cm})$, snow depth $(4.0-6.2 \mathrm{~cm}$ in Warren et al., 1999), snow density $\left(60.0-81.6 \mathrm{~kg} \mathrm{~m}^{-3}\right.$ in Warren et al., 1999), sea ice density $\left(7.6 \mathrm{~kg} \mathrm{~m}^{-3}\right.$ from data in Romanov (2004) and calculated in Tilling et al., 2015), sea ice concentration (5\% according to the NSIDC at http://nsidc.org/data/ docs/daac/nsidc0051_gsfc_seaice.gd.html) and sea ice extent (20 000-30 $000 \mathrm{~km}^{2}$ according to the NSIDC at http://nsidc. org/arcticseaicenews/faq/\#error_bars). Uncertainties in seawater density are neglected because they have a negligible impact (Kurtz et al., 2013; Ricker et al., 2014).

Errors in our freeboard estimates arise through speckle in the radar echoes, which averages $8 \mathrm{~cm}$ across the Arctic but decorrelates from one measurement to the next, and from uncertainties in sea surface height, which may be correlated in space due to our interpolation scheme based on a linear regression of measurements along $200 \mathrm{~km}$ sections of the ground track. We examined the variability of sea surface heights over this scale, and their standard deviation at orbit crossing points is $4 \mathrm{~cm}$. As a conservative estimate, we assume that this variability remains correlated within the $200 \mathrm{~km}$ window of our freeboard calculation and include it as an additional source of uncertainty in our gridded product. The freeboard error is then a combination of that due to spatially uncorrelated speckle on floe heights and that due to spatially correlated errors in the interpolation of sea surface heights. This results in a $2 \mathrm{~cm}$ freeboard uncertainty, which scales to $\sim 20 \mathrm{~cm}$ thickness, or $11 \%$ of a typical growth season thickness of $1.8 \mathrm{~m}$ (Tilling et al., 2015) for our gridded 28-day product.

To calculate uncertainties in sea ice volume, we compute the monthly rate of change of volume with respect to each parameter that has an associated error. We do this by individually adjusting the value for each parameter 6 times at even increments and recomputing the volume each time. The computed rates of change are then multiplied by the error in each parameter in question to estimate their partial contributions to the total volume error. Finally, we combine the monthly contribution to the volume error for all significant error sources in a root-sum-square manner to arrive at an estimate of the total monthly sea ice volume error:

$\sigma_{\mathrm{V}}=\sqrt{\left(\frac{\partial V}{\partial h_{\mathrm{s}}} \cdot \sigma_{h_{\mathrm{S}}}\right)^{2}+\left(\frac{\partial V}{\partial \rho_{\mathrm{s}}} \cdot \sigma_{\rho_{\mathrm{S}}}\right)^{2}+\left(\frac{\partial V}{\partial \rho_{\mathrm{i}}} \cdot \sigma_{\rho_{\mathrm{i}}}\right)^{2}+\left(\frac{\partial V}{\partial e_{\mathrm{i}}} \cdot \sigma_{e_{\mathrm{i}}}\right)^{2}+\sigma_{V_{\mathrm{c}}}^{2}}$,

where $\sigma_{\mathrm{V}}$ is the uncertainty in sea ice volume in a given month, $V$ is sea ice volume, $h_{\mathrm{s}}$ is Arctic-wide snow depth, $\sigma_{h_{\mathrm{s}}}$ is the uncertainty in snow depth, $\rho_{\mathrm{S}}$ is Arctic-wide snow density, $\sigma_{\rho_{\mathrm{S}}}$ is the uncertainty in snow density, $\rho_{\mathrm{i}}$ is Arcticwide ice density, $\sigma_{\rho_{\mathrm{i}}}$ is the uncertainty in sea ice density, $e_{\mathrm{i}}$ is sea ice extent, $\sigma_{e_{i}}$ is the uncertainty in sea ice extent, and $\sigma_{\mathrm{V}_{\mathrm{c}}}$ is the uncertainty in sea ice volume due to uncertainty in sea ice concentration. We estimate that year-to-year un- certainties in Arctic-wide sea ice volume are typically about $13.5 \%$, with small variations from month to month (Tilling et al., 2015).

Estimating local errors in sea ice thickness is complicated due to a lack of knowledge of the distances over which the contributing factors decorrelate. The main factors for which this information is important and lacking are snow depth, snow density and sea ice density. In our sea ice volume error budget, we estimate their uncertainty over large scales as the standard deviation of monthly averaged sparse field observations collected across the 9 million $\mathrm{km}^{2}$ central Arctic region. However, these factors and their variability are influenced by synoptic-scale meteorology, and we suppose that the length scale over which they are correlated is comparable to that of a typical polar vortex around $2000 \mathrm{~km}$ in diameter (http://www.cpc.ncep.noaa.gov/ products/stratosphere/polar/polar.shtml). Taking snow depth as an example, over areas that are large in comparison to this correlation scale, the variability of spatially averaged snowfall fluctuations will diminish in the ratio $1 / \sqrt{n}$, where $n$ is the effective number of independent values of accumulation sampled. We take $n \sim A /\left(\pi 2000^{2}\right)$, where $A$ is the area in square kilometres. If $n<1$, we set it equal to 1 . For the 9 million $\mathrm{km}^{2}$ central Arctic region, over which the largescale sea ice volume and thickness uncertainty is estimated to be $13.5 \%, n \sim 3$, leading to an uncertainty of $23 \%$. Using this approach and accounting additionally for short-scale correlated errors in freeboard associated with interpolating sea surface heights, we estimate the uncertainty in sea ice thickness increases to $25 \%$ at the $5 \mathrm{~km}$ scale of our 28-day NRT grid.

We acknowledge that this is only a first attempt to characterize local uncertainty in sea ice thickness, and that more detailed observations of snow depth, snow density and sea ice density are required to establish the extent to which their variability impacts on the retrieval accuracy. However, a $25 \%$ local error in our gridded 28-day estimates of Arctic sea ice thickness derived from CryoSat- 2 observations corresponds to an uncertainty of $45 \mathrm{~cm}$ for a typical thickness of $1.8 \mathrm{~m}$. This uncertainty is consistent with the spread of differences relative to independent estimates acquired from airborne and ocean-based platforms $(34-66 \mathrm{~cm}$ in Tilling et al., 2015). However, grid cell thickness uncertainty will increase with fewer days of data coverage. For example, for 2 days of data the averaged freeboard measurements often come from just one satellite pass. Therefore the full $4 \mathrm{~cm}$ uncertainty in sea surface height contributes to the freeboard error, which scales to $\sim 40 \mathrm{~cm}$ for thickness, or $22 \%$ of a typical thickness of $1.8 \mathrm{~m}$. Combined with the error of $23 \%$ from other sources this brings the total error on the 2-day $5 \mathrm{~km}$ grid sea-ice-thickness data to $32 \%$.

To assess the reliability of the NRT sea ice data set we compared it to values derived from the final CryoSat-2 data release (the archive product), which have shown excellent agreement with an extensive set of independent observations 

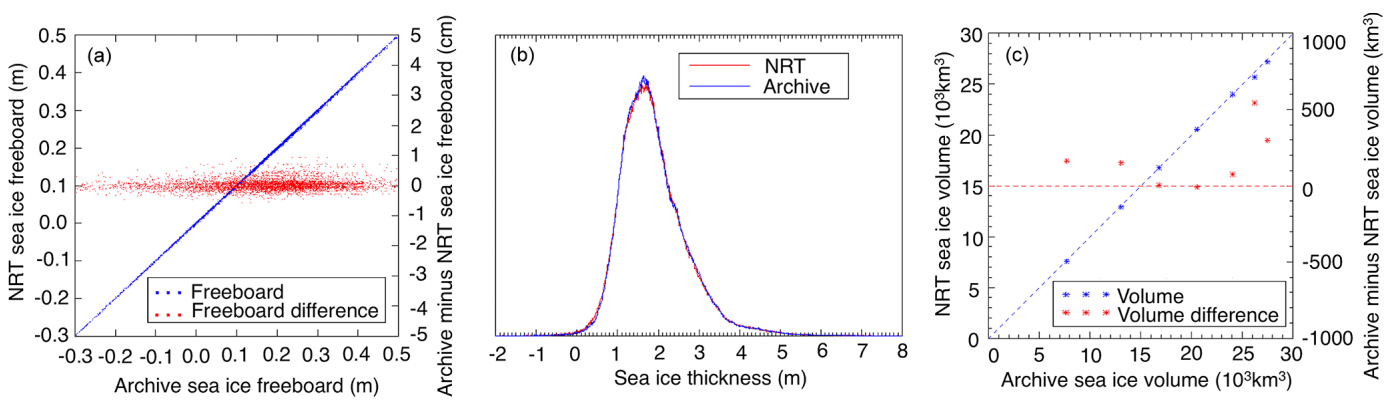

Figure 2. Comparison of near-real-time (NRT) and archive estimates of Arctic sea ice freeboard, thickness and volume, from CryoSat-2. (a) Cross-plot of point-by-point sea ice freeboard for an Arctic pass in April 2015. Also shown is the difference (archive minus NRT) in sea ice freeboard between the data sets. (b) Normalized distribution of NRT and archive thickness estimates over the period October 2014-April 2015 for all grid cells where measurements are available for both data sets. (c) Cross-plot of sea ice volume for October $2014-$ April 2015. Also shown is the difference (archive minus NRT) in sea ice volume between the data sets.

(Tilling et al., 2015). It is currently not possible to evaluate the NRT product directly against in situ measurements, as the overlap between coverage periods is too short. During archive processing we use final sea ice concentration from NSIDC (Cavalieri et al., 1996), rather than the NRT concentration data used in NRT sea ice calculations. Aside from this, the CryoSat-2 SAR and SARIn mode data are processed identically to the NRT case. First, we assessed our processing at orbit scale by calculating point-by-point differences of NRT and archive sea ice freeboards using a single track of CryoSat-2 data from April 2015 for which all geophysical corrections were present in both data sets. The track consisted of 3968 lead and 5246 freeboard measurements for the NRT data compared with 3970 lead and 5242 freeboard measurements for the archive data. Along this track, NRT and archive freeboards showed excellent agreement, with a mean difference of $0.02 \mathrm{~cm}$ (Fig. 2a). We then compared sea ice thickness and volume based on the NRT and archive products, using 7 months of data acquired between October 2014 and April 2015, which corresponds to a season of ice growth. The thickness comparison was done over the $5 \mathrm{~km}$ square grid on which NRT data are output. In general, our NRT and archive estimates of sea ice thickness are in excellent agreement, with a mean difference of $0.9 \mathrm{~cm}$ (Fig. 2b). NRT and archive estimates of sea ice volume are also in excellent agreement, with an average difference of $175 \mathrm{~km}^{3}$ (Fig. 2c) across the entire Arctic region. The negative freeboard and thickness values apparent in Fig. 2a and b respectively are a consequence of negative freeboard measurements that occur due to random noise in radar echoes from thin ice floes, caused by radar speckle. These freeboards are included in our processing to ensure that the average freeboard, and therefore thickness, is not biased high. Overall, differences between NRT and archive estimates of sea ice thickness and volume fall well within the corresponding estimates of their uncertainties (Tilling et al., 2015).

Our archive estimates of sea ice volume are larger than NRT estimates in part as they are computed using the final sea ice concentration data set, which contains higher values than its NRT counterpart. For example, we recalculated sea ice volume using the NRT sea ice thickness and final sea ice concentration data sets, and the departure from the archive estimate reduced to $100 \mathrm{~km}^{3}$. A contribution to the remaining difference is likely the combined absence of the wettropospheric, dry-tropospheric and inverse-barometer corrections in $93.8 \%$ of the Baseline-B fast-delivery CryoSat-2 data. This is reduced to $0.3 \%$ for Baseline-C data. The mean sea ice thickness for both the NRT and archive data sets is $\sim 1.8 \mathrm{~m}$, and there is no bias between them, with or without geophysical corrections applied. When the corrections are missing, the NRT and archive thickness values at any given location differ, on average, by just $1.1 \mathrm{~cm}$ with a standard deviation of $23.0 \mathrm{~cm}$ (Fig. 3a). This is reduced to $0.1 \mathrm{~cm}$ with a standard deviation of $7.4 \mathrm{~cm}$ when the corrections are present (Fig. 3b). There is no spatial pattern to these differences. Despite the improvement in performance of BaselineC NRT data compared with Baseline-B we conclude that the satellite orbits and on-ground processing applied to fastdelivery CryoSat-2 data are sufficient to determine accurate measurements of Arctic sea ice thickness and volume for both baselines. The thickness differences between the archive and NRT data products are not significant for either baseline given the estimated uncertainty on thickness and the typical thickness of sea ice floes.

\section{Results}

The spatial distribution of the NRT sea-ice-thickness data (Fig. 1) for any given time period depends on the nature of the CryoSat-2 orbit over that period. CryoSat-2 has an orbit repeat period of 369 days, which is built up by successive shifts of a 30-day repeat subcycle, meaning that uniform coverage of the Arctic Ocean is achieved every 30 days (Wingham et al., 2006). The density of orbit crossovers increases with latitude up to the CryoSat-2 limit of $88^{\circ} \mathrm{N}$ and with the 

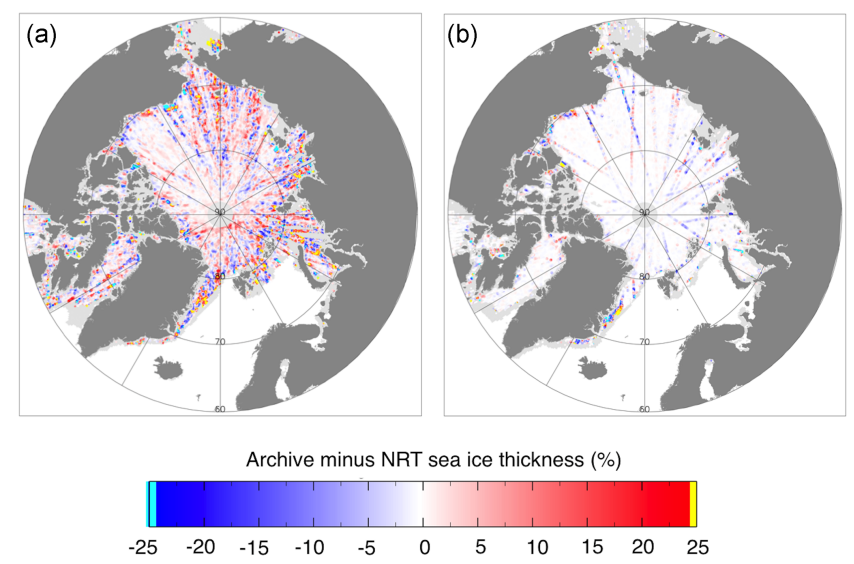

Figure 3. The impact of geophysical corrections on near-real-time (NRT) Arctic sea-ice-thickness estimates from CryoSat-2. (a) Percentage change in archive minus NRT thickness estimates for the final 28 days of March 2015. In March 2015 the wet-tropospheric, dry-tropospheric and inverse-barometer corrections were missing in $80 \%$ of cases. (b) Percentage change in archive minus NRT thickness estimates for the final 28 days of April 2015. In April 2015 the wet-tropospheric, dry-tropospheric and inverse-barometer corrections were missing in $0 \%$ of cases.

number of days of coverage. CryoSat-2 orbit patterns are visible in maps of thickness for 2-day (Fig. 1a, d) and 14-day (Fig. 1b, e) coverage. The orbits are clearer at lower latitudes, below about $80^{\circ}$ N. Over 28 days (Fig. 1c, f), almost complete coverage across the sea ice pack is achieved. However, there are still small areas of unmapped sea ice, and these typically occur at the ice edge (see Fig. 1). In these unmapped areas the sea ice concentration is above $15 \%$, which we use as the sea ice margin threshold, but below $75 \%$, which is the concentration required for a region to be classed as containing sea ice (see Sect. 2).

To determine the utility of the $5 \mathrm{~km}$ grid measurements of NRT sea ice thickness, we performed a detailed assessment of the spatial and temporal distribution of the data and compared these to the equivalent for archive data. Over the 2-, 14and 28-day time periods for which NRT data are available, we calculated the percentage of sea ice covered by NRT and archive data in $1^{\circ}$ latitude bands from 60 to $90^{\circ} \mathrm{N}$, for the final 2, 14 and 28 days of each month. This was done for data from October 2014 to April 2015, and data were averaged over all months (Fig. 4a). We produced the equivalent plot for the mean data separation in each latitude band, where separation is simply the square root of the number of measurements in each band divided by the sea-ice-covered area (Fig. 4b). For 28-day data coverage, sea ice at latitudes between 85 and $88^{\circ} \mathrm{N}$ is mapped in its entirety by the NRT and archive products and the data separation drops to $5.0 \mathrm{~km}$ in each $1^{\circ}$ latitude band, which is simply the grid separation. For 14-day coverage the CryoSat-2 orbit pattern achieves its maximum coverage for NRT data of $98 \%$, between 86 and $87^{\circ} \mathrm{N}$, but achieves $100 \%$ coverage for archive data between 86 and $88^{\circ} \mathrm{N}$. These correspond to mean data separations of 5.1 and $5.0 \mathrm{~km}$ (the grid separation). The maximum NRT coverage over 2 days is $91 \%$, between 87 and $88^{\circ} \mathrm{N}$, where the mean data separation is $5.2 \mathrm{~km}$. This increases to $99 \%$, between 87 and $88^{\circ} \mathrm{N}$ for archive data, with a mean data separation of $5.1 \mathrm{~km}$. For both NRT and archive data the percentage of ice mapped decreases with decreasing latitudes, and the separation between data points increases, although there is some fluctuation in these trends that is likely due to the shift in the CryoSat- 2 orbit pattern producing less favourable coverage for a given month. CryoSat-2 does not observe sea ice north of $88^{\circ} \mathrm{N}$, so the percentage of ice mapped drops to $0 \%$ for 2-, 14- and 28-day coverage in the region $88-90^{\circ} \mathrm{N}$ for both data sets. On average, the NRT sea-ice-thickness data maps 20,51 and $66 \%$ of the Arctic sea ice north of $60^{\circ} \mathrm{N}$ every 2,14 and 28 days respectively. This corresponds to a measurement within 14, 7 and $6 \mathrm{~km}$ of each location in the Arctic every 2,14 and 28 days. For archive data the coverage increases to 23,57 and $69 \%$ every 2,14 and 28 days respectively, which corresponds to a measurement within 13, 7 and $6 \mathrm{~km}$ of each location in the Arctic.

The distribution of NRT sea-ice-thickness measurements also varies with region and month, and the nature of the monthly variation depends on the region being observed. This is an important consideration for those wishing to use the data in a specific region of interest or over the entirety of the sea ice growth season. We calculated the percentage of ice cover mapped by the NRT product for six key oceanographic regions (Fig. 5a) for the final 28 days of each month of the 2014-2015 sea ice growth season (Fig. 5b), then compared this to the percentage of ice cover mapped by our archive data in the same regions (Fig. 5c). The percentage of the ice cover mapped in the Amerasian and Eurasian basins is high ( $\geq 76 \%$ for NRT data and $\geq 83 \%$ for archive data), with just a small increase over the growth season. Both regions are almost entirely covered in sea ice year-round, which means that the areal fraction of unmapped sea ice at the ice edge is fairly consistent throughout the year. However, this is not the case for regions with more seasonal ice cover, such as the Canadian Archipelago and Northwest Passage, Hudson Bay and the Beaufort Sea, where NRT and archive coverage improves throughout the growth season and peaks in February or March. In these regions, as the extent of the sea ice cover increases through winter, the unmapped area at the sea ice edge becomes a decreasing fraction of the icecovered area, and a greater percentage of the ice cover is mapped. In addition, as the sea ice concentration increases through winter, echoes from sea ice floes becomes less noisy and are more likely to be included in our processing. Coverage in the Greenland Sea generally improves throughout the growth season, although there is some variation in this pattern due to fluctuations in the width of the unmapped area at the sea ice edge, which could be a consequence of the rapid sea ice transport in this sector. Overall, coverage is lowest 

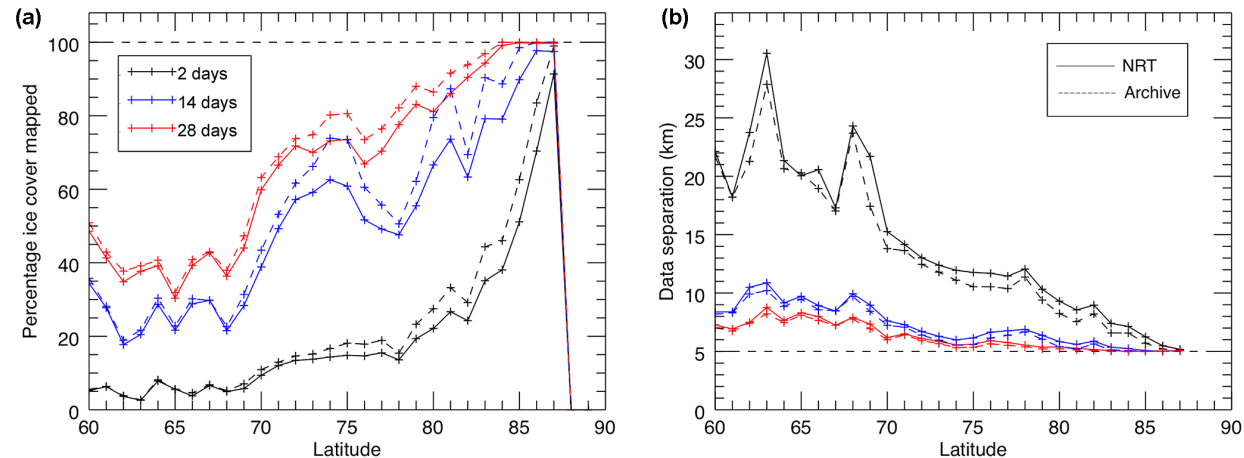

Figure 4. Spatial and temporal sampling of the Centre for Polar Observation and Modelling (CPOM) near-real-time (NRT) and archive Arctic sea-ice-thickness products, north of $60^{\circ}$ N. (a) Percentage of sea ice cover mapped in $1^{\circ}$ latitude bands, averaged over each month from October 2014 to April 2015. Data are plotted for the final 28, 14 and 2 days of all months. Solid lines show NRT data, dashed lines show archive data. (b) Mean separation between measurement points in $1^{\circ}$ latitude bands, averaged over each month from October 2014-April 2015. Data are plotted for the final 28, 14 and 2 days of all months. Solid lines show NRT data, dashed lines show archive data.
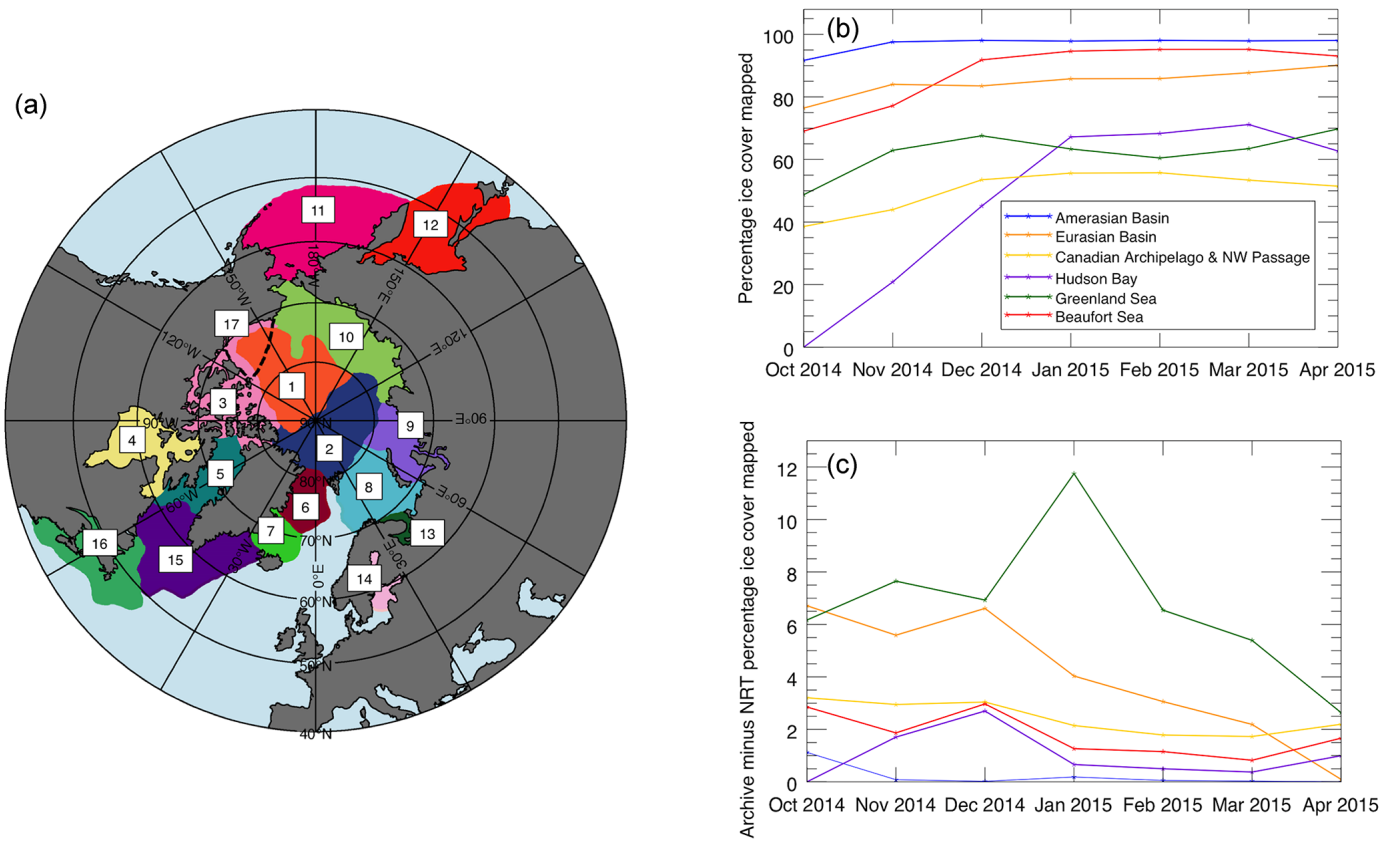

Figure 5. Regional and temporal sampling of the Centre for Polar Observation and Modelling (CPOM) near-real-time (NRT) and archive Arctic sea-ice-thickness products. (a) Arctic Ocean regions. The regions are the Amerasian Basin (1), Eurasian Basin (2), Canadian Archipelago and Northwest Passage (3), Hudson Bay and Foxe Basin (4), Baffin Bay (5), Greenland Sea (6), Iceland Sea (7), Barents Sea (8), Kara Sea (9), Siberian shelf seas (10), Bering Sea (11), Sea of Okhotsk (12), White Sea (13), Baltic Sea and surrounding gulfs (14), Labrador Sea (15), the Gulf of St Lawrence and Nova Scotia Peninsula (16) and the Beaufort Sea (17). Regions 1-10 encompass all autumn sea ice, and regions 1-16 encompass all spring sea ice. Region 17 is a subregion of regions 1 and 3. (b) Plot showing the percentage of sea ice cover mapped by the NRT product in each month for six key oceanographic basins. (c) Plot showing the difference (archive - NRT) in percentage ice cover mapped.

for the Greenland Sea, Canadian Archipelago and Northwest Passage and Hudson Bay. Due to the location of the Greenland Sea, there is also a persistent presence of unmapped sea ice along its eastern edge. The Canadian Archipelago and Northwest Passage and Hudson Bay are in close proximity to substantial coastal areas, where it is difficult to construct sea surface height due to the absence of leads in the sea ice pack. Although there is spatial variation in the coverage of the NRT sea-ice-thickness data, both with latitude (Fig. 4) and oceanographic basin (Fig. 5b), there is no significant spatial variability in the difference between the NRT and archive data coverage (Figs. 4, 5c). 
Table 1. Variations in the sampling of CryoSat-2 near-real-time (NRT) sea-ice-thickness products in 17 Arctic Ocean basins. Regions 1-10 encompass all October sea ice, and regions 1-16 encompass all March sea ice. Region 17 is a subregion of region 1 (Fig. 5a).

\begin{tabular}{|c|c|c|c|c|c|c|}
\hline & \multicolumn{6}{|c|}{ Data coverage (\% of ice cover mapped) } \\
\hline & \multicolumn{2}{|c|}{2 days } & \multicolumn{2}{|c|}{14 days } & \multicolumn{2}{|c|}{28 days } \\
\hline & Oct 2014 & Mar 2015 & Oct 2014 & Mar 2015 & Oct 2014 & Mar 2015 \\
\hline Amerasian Basin (1) & 33 & 38 & 78 & 82 & 92 & 98 \\
\hline Eurasian Basin (2) & 24 & 44 & 58 & 73 & 76 & 88 \\
\hline Canadian Archipelago and Northwest Passage (3) & 9 & 7 & 31 & 37 & 39 & 53 \\
\hline Hudson Bay (4) & 0 & 6 & 0 & 48 & 0 & 71 \\
\hline Baffin Bay (5) & 0 & 15 & 0 & 56 & 0 & 81 \\
\hline Greenland Sea (6) & 8 & 13 & 31 & 50 & 49 & 63 \\
\hline Iceland Sea (7) & 0 & 16 & 0 & 44 & 0 & 57 \\
\hline Barents Sea (8) & 0 & 9 & 17 & 32 & 18 & 47 \\
\hline Kara Sea (9) & 2 & 17 & 15 & 46 & 16 & 58 \\
\hline Siberian shelf seas (10) & 11 & 20 & 38 & 60 & 49 & 85 \\
\hline Bering Sea (11) & $\mathrm{n} / \mathrm{a}$ & 3 & $\mathrm{n} / \mathrm{a}$ & 35 & $\mathrm{n} / \mathrm{a}$ & 40 \\
\hline Sea of Okhotsk (12) & $\mathrm{n} / \mathrm{a}$ & 0 & $\mathrm{n} / \mathrm{a}$ & 21 & $\mathrm{n} / \mathrm{a}$ & 33 \\
\hline White Sea (13) & $\mathrm{n} / \mathrm{a}$ & 0 & $\mathrm{n} / \mathrm{a}$ & 6 & $\mathrm{n} / \mathrm{a}$ & 6 \\
\hline Baltic Sea and surrounding gulfs (14) & $\mathrm{n} / \mathrm{a}$ & 0 & $\mathrm{n} / \mathrm{a}$ & 0 & $\mathrm{n} / \mathrm{a}$ & 0 \\
\hline Labrador Sea (15) & $\mathrm{n} / \mathrm{a}$ & 1 & $\mathrm{n} / \mathrm{a}$ & 13 & $\mathrm{n} / \mathrm{a}$ & 19 \\
\hline Gulf of St Laurence and Nova Scotia Peninsula (16) & $\mathrm{n} / \mathrm{a}$ & $\mathrm{n} / \mathrm{a}$ & $\mathrm{n} / \mathrm{a}$ & $\mathrm{n} / \mathrm{a}$ & $\mathrm{n} / \mathrm{a}$ & $\mathrm{n} / \mathrm{a}$ \\
\hline Beaufort Sea (17) & 17 & 20 & 59 & 83 & 69 & 95 \\
\hline
\end{tabular}

We extended our analysis of NRT data sampling by calculating the percentage of sea ice mapped in all Arctic Ocean basins at the beginning and end of the sea ice growth season (Table 1) for the final 2, 14 and 28 days of each month. In each month the coverage improves with the number of days sampling, in every basin. The coverage also improves from October to March, for each time period and for all but one basin; the Canadian Archipelago/Northwest Passage experiences a drop in coverage over the growth season for the 2day observation period. However, this change is very small, and over short observation periods we would expect some variability in the proportion of ice cover mapped as a consequence of the CryoSat-2 orbital repeat pattern. This becomes more important in regions such as the Canadian Archipelago, where there is a high fraction of land interspersed with ocean. The Bering Sea, the Sea of Okhotsk, the White Sea, the Baltic Sea and surrounding Gulfs and the Labrador Sea have the smallest proportional ice cover mapped in March 2015. These are regions of highly seasonal sea ice cover, and by the end of the growth season the unmapped area at the ice edge still constitutes a sizable fraction of the ice-covered area. In addition, they are all southerly basins (below $70^{\circ} \mathrm{N}$ ), which are sampled with reduced spatial density by CryoSat-2. The most extensively sampled areas are in the central Arctic the Amerasian and Eurasian basins - which experience substantial year-round sea ice cover and are at high latitudes. We conclude that the location, seasonality and dynamic nature of any sea ice region are important considerations when assessing the reliability of the NRT Arctic sea-ice-thickness product.

\section{Discussion and conclusions}

We have shown that NRT estimates of sea ice thickness determined from fast-delivery CryoSat-2 data can be computed within a few days of the raw data acquisition and with a certainty that is comparable to that of the standard archive product which is typically available 6 months later. This allows for timely and reliable assessments of local and regional sea ice conditions, which should benefit activities that depend on such data. A good example is seasonal forecasts of Arctic sea ice properties, which have previously utilized sparse airborne measurements to adjust model-based initial ice-thickness distributions (Lindsay et al., 2012). Although of coarser spatial resolution, our NRT thickness estimates complement the airborne data because of their wider spatial and temporal extent (Posey et al., 2015; Chevallier and SalasMelia, 2012), and even though the data do not extend into the summer season, their use should nevertheless lead to improved model skill (Day et al., 2014; Sigmond et al., 2013). A previous study (Rinne and Similä, 2016) has highlighted the potential value of fast-delivery CryoSat- 2 data for the classification of sea ice into discrete stages of its development - thin $(<70 \mathrm{~cm})$ and thick $(>70 \mathrm{~cm})$ FYI and MYI in the Kara Sea. We have extended this initial analysis of the mission potential to provide continuous measurements of sea ice thickness across the entire Northern Hemisphere. Together with records of NRT sea ice concentration (Cavalieri et al., 1996; Maslanik and Stroeve, 1999), which are also available in NRT, NRT estimates of sea ice thickness determined from CryoSat- 2 will allow routine assessments 
of Arctic environmental conditions (Stroeve et al., 2005) to report additional changes in sea ice thickness and volume.

In addition to the CryoSat- 2 measurements, our NRT seaicethickness estimates depend also on timely availability of sea ice concentration estimates (Maslanik and Stroeve, 1999) and of classification of sea ice type (http://osisaf.met.no/p/ ice/\#type). The sea ice concentration and sea-ice-type data sets are currently available to us 2 days and 1 day after their measurements respectively. Because the fast-delivery CryoSat-2 data are typically available 1-3 days after acquisition, the latency of the NRT sea-ice-thickness product is in practice limited by the altimeter data. A more rapidly delivered product, to support by day-to-day activities in the Arctic, would first require improvements in the latency of the CryoSat- 2 data, followed by either improvements in the latency of sea ice concentration data or the use of older sea ice concentration measurements as an approximation.

The NRT estimates are of comparable accuracy to those produced using the final release CryoSat- 2 data, with a mean difference of $0.9 \mathrm{~cm}$ between NRT and archive estimates of sea ice thickness. The NRT and archive thickness differences, although small, vary temporally. The differences are reduced when all geophysical corrections are present in the fast-delivery CryoSat- 2 data, which is the case in $99.7 \%$ of the data since 26 March 2015, when the ESA on-ground processing chain switched from Baseline-B to Baseline-C. There is no spatial variability in the differences between our NRT and archive data products. For the period from October 2014 to April 2015, the NRT data set covered an average of 20,51 and $66 \%$ of the Arctic sea ice north of $60^{\circ} \mathrm{N}$ every 2 , 14 and 28 days respectively. This is equivalent to a measurement within 14, 7 and $6 \mathrm{~km}$ of each location in the Arctic every 2, 14 and 28 days. However, there are temporal and spatial variations in the data coverage. The time of year, location and dynamic nature of any region of interest must be considered when assessing the reliability of the data. The next major step in the advancement of the data is to develop improved estimates of snow loading on Arctic sea ice. We also intend to investigate the impact of different gridding methods, including the application of a distance weighting to our gridded NRT sea-ice-thickness product. Our sea ice thickness and volume error budget could be further constrained with improved knowledge on uncertainties in snow loading and sea ice density, and also by accounting for uncertainties in the propagation speed of the radar signals through the snow pack.

\section{Data availability}

Our NRT sea ice thickness and volume data are publicly available on the CPOM UCL data portal at http://www.cpom. ucl.ac.uk/csopr/seaice.html.
The fast-delivery CryoSat-2 Level $1 \mathrm{~b}$ radar altimeter data used for this work are available on request via ftp at ftp:// science-pds.cryosat.esa.int.

The NRT DMSP SSMIS daily polar gridded sea ice concentration data required for this work are available from NSIDC via ftp at ftp://sidads.colorado.edu/pub/DATASETS/ nsidc0081_nrt_nasateam_seaice/, and the NRT sea ice type maps are available from OSI SAF at http://osisaf.met.no/p/ ice/\#type.

Author contributions. Rachel L. Tilling and Andy Ridout developed and analysed the satellite observations. Andrew Shepherd supervised the work. Rachel L. Tilling, Andy Ridout and Andrew Shepherd wrote the paper. All authors commented on the text.

Acknowledgements. We wish to thank those who provided the timely ancillary data that we required to deliver a NRT product: ESA, for the fast-delivery CryoSat-2 Level $1 b$ data; OSI SAF, for their sea ice type data; and NSIDC, for hosting the NRT sea ice concentration data. This work was funded by the UK Natural Environment Research Council, with support from the UK National Centre for Earth Observation.

Edited by: C. Haas

Reviewed by: two anonymous referees

\section{References}

Alexandrov, V., Sandven, S., Wahlin, J., and Johannessen, O. M.: The relation between sea ice thickness and freeboard in the Arctic, The Cryosphere, 4, 373-380, doi:10.5194/tc-4-373-2010, 2010.

Cavalieri, D. J., Parkinson, C. L., Gloersen, P., and Zwally, H. J.: Sea ice concentrations from Nimbus-7 SMMR and DMSP SSM/ISSMIS passive microwave data [concentration], National Snow and Ice Data Center, Boulder, CO, USA, 1996 (updated yearly).

Chevallier, M. and Salas-Melia, D.: The Role of Sea Ice Thickness Distribution in the Arctic Sea Ice Potential Predictability: A Diagnostic Approach with a Coupled GCM, J. Climate, 25, 30253038, 2012.

CPOM UCL: NRT Arctic sea ice thickness and volume data, available at: http://www.cpom.ucl.ac.uk/csopr/seaice.html, last access: August 2016.

Day, J. J., Tietsche, S., and Hawkins, E.: Pan-Arctic and regional sea ice predictability: Initialization month dependence, J. Climate, 27, 4371-4390, 2014

ESA Earth Online: CryoSat-2 L1b data, available at: ftp:// science-pds.cryosat.esa.int, last access: August 2016.

Hebert, D. A., Allard, R. A., Metzger, E. J., Posey, P. G., Preller, R. H., Wallcraft, A. J., Phelps, M. W., and Smedstad, O. M.: Short-term sea ice forecasting: An assessment of ice concentration and ice drift forecasts using the US Navy's Arctic Cap Nowcast/Forecast System, J. Geophys. Res.-Oceans, 120, 8327-8345, 2015. 
Kurtz, N. T. and Farrell, S. L.: Large-scale surveys of snow depth on Arctic sea ice from Operation IceBridge, Geophys. Res. Lett., 38, L20505, doi:10.1029/2011GL049216, 2011.

Kurtz, N. T., Farrell, S. L., Studinger, M., Galin, N., Harbeck, J. P., Lindsay, R., Onana, V. D., Panzer, B., and Sonntag, J. G.: Sea ice thickness, freeboard, and snow depth products from Operation IceBridge airborne data, The Cryosphere, 7, 1035-1056, doi:10.5194/tc-7-1035-2013, 2013.

Kurtz, N. T., Galin, N., and Studinger, M.: An improved CryoSat-2 sea ice freeboard retrieval algorithm through the use of waveform fitting, The Cryosphere, 8, 1217-1237, doi:10.5194/tc-8-12172014, 2014.

Kwok, R., Cunningham, G. F., Wensnahan, M., Rigor, I., Zwally, H. J., and Yi, D.: Thinning and volume loss of the Arctic Ocean sea ice cover: 2003-2008, J. Geophys. Res., 114, C07005, doi:10.1029/2009JC005312, 2009.

Lindsay, R. W., Haas, C., Hendricks, S., Hunkeler, P., Kurtz, N., Paden, J., Panzer, B., Sonntag, J., Yungel, J., and Zhang, J.: Seasonal forecasts of Arctic sea ice initialized with observations of ice thickness, Geophys. Res. Lett., 39, L21502, doi:10.1029/2012GL053576, 2002.

Maslanik, J. and Stroeve, J. C.: Near-Real-Time DMSP SSM/ISSMIS daily polar gridded sea ice concentrations [concentration], National Snow and Ice Data Center, Boulder, CO, USA, 1999 (updated daily).

Meier, W. N., Hovelsrud, G. K., van Oort, B. E. H., Key, J. R., Kovacs, K. M., Michel, C., Haas, C., Granskog, M. A., Gerland, S., Perovich, D. K., Makshtas, A., and Reist, J. D.: Arctic sea ice in transformation: A review of recent observed changes and impacts on biology and human activity, Rev. Geophys., 52, 185217, 2014.

Nurser, A. J. G. and Bacon, S.: The Rossby radius in the Arctic Ocean, Ocean Sci., 10, 967-975, doi:10.5194/os-10-967-2014, 2014.

OSI SAF (Ocean and Sea Ice Satellite Application Facility): NRT sea ice type data, available at: http://osisaf.met.no/p/ice/\#type, last access: August 2016.

Peacock, N. R. and Laxon, S. W.: Sea surface height determination in the Arctic Ocean from ERS altimetry, J. Geophys. Res., 109, C07001, doi:10.1029/2001JC001026, 2004.

Posey, P. G., Metzger, E. J., Wallcraft, A. J., Hebert, D. A., Allard, R. A., Smedstad, O. M., Phelps, M. W., Fetterer, F., Stewart, J. S., Meier, W. N., and Helfrich, S. R.: Improving Arctic sea ice edge forecasts by assimilating high horizontal resolution sea ice concentration data into the US Navy's ice forecast systems, The Cryosphere, 9, 1735-1745, doi:10.5194/tc-9-1735-2015, 2015.

Ricker, R., Hendricks, S., Helm, V., Skourup, H., and Davidson, M.: Sensitivity of CryoSat-2 Arctic sea-ice freeboard and thickness on radar-waveform interpretation, The Cryosphere, 8 , 16071622, doi:10.5194/tc-8-1607-2014, 2014.
Rinne, E. and Similä, M.: Utilisation of CryoSat-2 SAR altimeter in operational ice charting, The Cryosphere, 10, 121-131, doi:10.5194/tc-10-121-2016, 2016.

Romanov, I. P.: Morphometric characteristics of ice and snow in the Arctic Basin: Aircraft landing observations from the former Soviet Union, 1928-1989, National Snow and Ice Data Center, Boulder, CO, USA, 2004.

Sigmond, M., Fyfe, J. C., Flato, G. M., Kharin, V. V., and Merryfield, W. J.: Seasonal forecast skill of Arctic sea ice area in a dynamical forecast system, Geophys. Res. Lett., 40, 529-534, 2013.

Stewart, E. J., Howell, S. E. L., Draper, D., Yackel, J., and Tivy, A.: Sea ice in Canada's Arctic: Implications for cruise tourism, Arctic, 60, 370-380, 2007.

Stroeve, J. C., Serreze, M. C., Fetterer, F., Arbetter, T., Meier, W., Maslanik, J., and Knowles, K.: Tracking the Arctic's shrinking ice cover: Another extreme September minimum in 2004, Geophys. Res. Lett., 32, L04501, doi:10.1029/2004GL021810, 2005.

Tilling, R. L., Ridout, A., Shepherd, A., and Wingham, D. J.: Increased Arctic sea ice volume after anomalously low melting in 2013, Nat. Geosci., 8, 643-646, 2015.

U.S. Navy: U.S. Navy Arctic Roadmap 2014-2030, CreateSpace Publishing, Washington, D.C., USA, 2014.

Wadhams, P., Tucker, W. B. I., Krabill, W. B., Swift, J. C., Comiso, J. C., and Davis, N. R.: Relationship between sea ice freeboard and draft in the Arctic Basin, and implications for ice thickness monitoring, J. Geophys. Res., 97, 20325-20334, 1992.

Warren, S. G., Rigor, I. G., Untersteiner, N., Radionov, V. F., Bryazgin, N. N., Aleksandrov, Y. I., and Colony, R.: Snow depth on Arctic sea ice, J. Climate, 12, 1814-1829, 1999.

Webster, M. A., Rigor, I. G., Nghiem, S. V., Kurtz, N. T., Farrell, S. L., Perovich, D. K., and Sturm, M.: Interdecadal changes in snow depth on Arctic sea ice, J. Geophys. Res.-Oceans, 119, 5395-5406, 2014.

Wingham, D. J., Francis, C. R., Baker, S., Bouzinac, C., Brockley, D., Cullen, R., de Chateau-Thierry, P., Laxon, S. W., Mallow, U., Mavrocordatos, C., Phalippou, L., Ratier, G., Rey, L., Rostan, F., Viau, P., and Wallis, D. W.: CryoSat: A mission to determine the fluctuations in Earth's land and marine ice fields, Adv. Space Res., 37, 841-871, doi:10.1016/j.asr.2005.07.027, 2006.

Woods Hole Oceanographic Institution: Beaufort Gyre Exploration Project, available at: http://www.whoi.edu/beaufortgyre, last access: August 2016. 